Journal of Mathematics and Informatics

Vol. 11, 2017, 17-19

ISSN: 2349-0632 (P), 2349-0640 (online)

Published 11 December 2017

www.researchmathsci.org

DOI: http://dx.doi.org/10.22457/jmi.v1 la3

Journal of

Mathematics and

Informatics

\title{
Pentagonal Numbers, Heptagonal Numbers and Pythagorean Triangles
}

\author{
G.Jeyakrishnan ${ }^{1}$ and G.Komahan ${ }^{2}$ \\ ${ }^{1}$ Department of Mathematics, Kings College of Engineering, \\ Punalkulam, Pudukkottai (Dt) -613303, Tamilnadu, India \\ Email: jeyakrishnang@gmail.com \\ ${ }^{2}$ Department of Mathematics, A.V.V.M Sri Pushpam College \\ Poondi, Tamilnadu, India
}

Received 1 November 2017; accepted 8 December 2017

Abstract. Oblong numbers as figuret numbers, which were first studied by the Pythagoreans are studied in terms of special Pythagorean Triangles. The two consecutive sides and their perimeters of Pythagorean triangles are investigated. In this study, the perimeter of Pythagorean triangles are obtained as addition of pentagonal and heptagonal numbers.

Keywords: Pentagonal numbers, Heptagonal numbers, Pythagorean Triangles, Diophantine equation.

\section{AMS Mathematics Subject Classification (2010): 11D09}

\section{Introduction}

Mathematicians all over the ages have been fascinated by the Pythagorean Theorem and are solving many problems related to it thereby developing mathematics. Integral solutions [1] and [2] and special Pythagorean triangles are generated by [3,4]. [5] Have given perimeter of Pythagorean triangles with their perimeter as addition of pentagonal and heptagonal numbers. Such triangles with two consecutive sides and perimeter as addition of pentagonal and heptagonal numbers are also studied.

\section{Method of analysis}

The primitive solutions of the Pythagorean Equation,

$\mathrm{X}^{2}+\mathrm{Y}^{2}=\mathrm{Z}^{2}$, is given by [5]

$X=m^{2}-n^{2}, Y=2 m n, Z=m^{2}+n^{2}$

for some integers $m, n$ of opposite parity such that $m>n>0$ and $(m, n)=1$

\subsection{Perimeter is an addition of pentagonal and heptagonal numbers}

Definition 1. A natural number $\mathrm{P}$ is called addition of pentagonal and heptagonal number if it can be written in the form $\frac{\left(3 \alpha^{2}-\alpha\right)}{2}+\frac{\left(5 \alpha^{2}-3 \alpha\right)}{2}=2\left(2 \alpha^{2}-\alpha\right), \alpha \in N$ 


\section{G.Jeyakrishnan and G.Komahan}

If the perimeter of the Pythagorean triangle $(\mathrm{X}, \mathrm{Y}, \mathrm{Z})$ is addition of pentagonal and heptagonal number $\alpha$, then

$\mathrm{X}+\mathrm{Y}+\mathrm{Z}=2\left(2 \alpha^{2}-\alpha\right)=\mathrm{P}$

From the equations (2) and (3)

$2 \mathrm{~m}^{2}+2 \mathrm{mn}=2\left(2 \alpha^{2}-\alpha\right), \alpha \varepsilon \mathrm{N}$.

$\mathrm{m}(\mathrm{m}+\mathrm{n})=\alpha(2 \alpha-1)$

\subsection{Hypotenuse and one leg are consecutive}

In such cases, $\mathrm{m}=\mathrm{n}+1$

This gives equation (4) as

$(\mathrm{n}+1)(2 \mathrm{n}+1)=\alpha(2 \alpha-1)$

Take $\alpha=\mathrm{n}+1$

Equations (2), (5) \& (6) give solution of equations (1) in correspondence with equations (3) and (4)

$$
\begin{array}{ll}
\text { i.e., } & X=2 n+1 ; \\
& Y=2 n(n+1) ; \\
& Z=2 n(n+1)+1 ;
\end{array}
$$

First ten such special Pythagorean triangles $(\mathrm{X}, \mathrm{Y}, \mathrm{Z})$ are given in the Table 1 below:

Table 1: Special Pythagorean Triangles

\begin{tabular}{|c|c|c|c|c|c|c|}
\hline S. No. & $\mathbf{n}$ & $\boldsymbol{\alpha}$ & $\mathbf{P}$ & $\mathbf{X}$ & $\mathbf{Y}$ & $\mathbf{Z}$ \\
\hline 1 & 1 & 2 & 12 & 3 & 4 & 5 \\
\hline 2 & 2 & 3 & 30 & 5 & 12 & 13 \\
\hline 3 & 3 & 4 & 56 & 7 & 24 & 25 \\
\hline 4 & 4 & 5 & 90 & 9 & 40 & 41 \\
\hline 5 & 5 & 6 & 132 & 11 & 60 & 61 \\
\hline 6 & 6 & 7 & 182 & 13 & 84 & 85 \\
\hline 7 & 7 & 8 & 240 & 15 & 112 & 113 \\
\hline 8 & 8 & 9 & 306 & 17 & 144 & 145 \\
\hline 9 & 9 & 10 & 380 & 19 & 180 & 181 \\
\hline 10 & 10 & 11 & 462 & 21 & 220 & 221 \\
\hline
\end{tabular}


Pentagonal Numbers, Heptagonal Numbers and Pythagorean Triangles

Table 2: Verification of $\mathrm{X}^{2}+\mathrm{Y}^{2}=\mathrm{Z}^{2}$ and $\mathrm{X}+\mathrm{Y}+\mathrm{Z}=2 \alpha(2 \alpha-1)$

\begin{tabular}{|c|c|c|c|c|c|}
\hline S.No & $\mathbf{X}^{\mathbf{2}}$ & $\mathbf{Y}^{\mathbf{2}}$ & $\mathbf{X}^{\mathbf{2}+\mathbf{Y}^{\mathbf{2}}}$ & $\mathbf{Z}^{\mathbf{2}}$ & $\mathbf{X}+\mathbf{Y}+\mathbf{Z}=\mathbf{2} \boldsymbol{\alpha ( \mathbf { 2 } \boldsymbol { \alpha - 1 } )}$ \\
\hline 1 & 9 & 16 & 25 & 25 & $12=2.2 .3$ \\
\hline 2 & 25 & 144 & 169 & 169 & $30=2.3 .5$ \\
\hline 3 & 49 & 576 & 625 & 625 & $56=2.4 .7$ \\
\hline 4 & 81 & 1600 & 1681 & 1681 & $90=2.5 .9$ \\
\hline 5 & 121 & 3600 & 3721 & 3721 & $132=2.6 .11$ \\
\hline 6 & 169 & 7056 & 7225 & 7225 & $182=2.7 .13$ \\
\hline 7 & 225 & 12544 & 12769 & 12769 & $240=2.8 .15$ \\
\hline 8 & 289 & 20736 & 21025 & 21025 & $306=2.9 .17$ \\
\hline 9 & 361 & 32400 & 32761 & 32761 & $380=2.10 .19$ \\
\hline 10 & 441 & 48400 & 48841 & 48841 & $462=2.11 .21$ \\
\hline
\end{tabular}

3. Observations and conclusion

1. $(X+Y-Z)^{2}=(Y+Z-2 X+1)$

2. $(X+Z-Y)^{2}=(Y+Z+2 X+1)$

3. $\mathrm{Y}+\mathrm{Z}=\mathrm{X}^{2}$

\section{REFERENCES}

1. M.A.Gopalan, S.Manju and N.Vanitha, Integral solutions of ternary quadratic equation XY + YZ = ZX; Antarctica J. Math., 5(1) (2008) 1-5.

1. M.A.Gopalan and Kalinga Rani, On ternary quadratic equation $x^{2}+y^{2}=z^{2}+8$; Impact J. of Science and Technology, 5(1) (2011) 39-43.

2. M.A.Gopalan and P.Vijalakshmi, Special Pythagorean triangles generated through the integral solutions of the equation $\mathrm{y}^{2}=\left(\mathrm{k}^{2}+1\right) \mathrm{x}^{2}+1$, Antarctica $J$. Math., 7(5) (2010) 503-507.

3. M.A.Gopalan and S.Devibala, Special Pythagorean triangle, Acta Ciencia Indica, 31(1) M2005) 39-40.

4. M.A.Gopalan and G.Janaki, Pythagorean triangles with perimeter as a pentagonal number, Antarctica J. Math., 5(2) (2008) 15-18.

5. I.Niven and Herbert S. Zuckerman, An Introduction to the Theory of Numbers, Wiley Eastern Limited, New Delhi, 1976. 